\title{
Biopolítica, soberanía y excepción. Una revisión crítica de la obra de Giorgio Agamben
}

Biopolitics, sovereignty and exception. A critical review of Giorgio Agamben's work

Biopolitica, soberania e exceção. Uma revisão critica da obra de Giorgio Agamben

Biopolitique, souveraineté et exception. Une révision critique de l'œuvre de Giorgio Agamben

\author{
Mauro Benente iD \\ Doctor en Derecho \\ Universidad Nacional de José C. Paz, José C. Paz - Argentina. \\ Doctor en Derecho por la Universidad de Buenos Aires (Argentina). \\ Director del Instituto Interdisciplinario de Estudios Constitucionales de la \\ Universidad Nacional de José C. Paz (Argentina) \\ Correo electrónico: mbenente@unpaz.edu.ar
}

Cómo citar este artículo:

Benente, M. (2019). Biopolítica, soberanía y excepción. Una revisión crítica de la obra de Giorgio Agamben. Revista de la Facultad de Derecho y Ciencias Políticas, 49 (130),pp. 202-224. doi: http://dx.doi.org/10.18566/rfdcp.v49n130.a09

Recibido: 14 de enero de 2016.

Aprobado: 23 de agosto de 2018. 


\section{Resumen}

Luego de describir detalladamente el funcionamiento del poder disciplinario, Michel Foucault avanzó con menos precisión en la conceptualización de la biopolítica, de un tipo de regulación de poblaciones que reduce la vida a sus dimensiones biológicas. Retomando, pero también corrigiendo estos desarrollos, Giorgio Agamben marcó una relación estructural entre soberanía y vida, mediadas por el estado de excepción. En este trabajo me interesa remarcar que los conceptos de soberanía y estado de excepción no son aplicables ni siquiera para el nazismo, el único ejemplo histórico analizado por el autor italiano.

\section{Palabras clave}

Poder, soberanía, vida, estado de excepción, nazismo.

\section{Abstract}

After describing in detail the functioning of the disciplinary power, Michel Foucault advanced with less precision in the conceptualization of biopolitics, of a type of population regulation that reduces life to its biological dimensions. Retaking, yet also correcting these developments, Giorgio Agamben marked a structural relationship between sovereignty and life, mediated by the state of exception. In this work I am interested in remarking that the concepts of sovereignty and state of exception are not even applicable to Nazism, the only historical example analyzed by the Italian author.

\section{Key Words}

Power; Sovereignty; Life; State of exception; Nazism.

\section{Resumo}

Despois de descrever em profundidade o funcionamento do poder disciplinar, Michel Foucault avançou com menor detalhe no conceito de biopolitica, isto é, o controle de populações que reduz a vida a suas dimensões biológicas. Nesse sentido, Giorgio Agamben recupera o conceito, mas corrige esses desenvolvimentos, assim ele assinala a relação estrutural entre soberania e vida devida ao estado de exceção. Nesse artigo tento estabelecer que os conceitos de soberania e estado de exceção não são aplicáveis nem mesmo para o nazismo, o único exemplo histórico que o autor italiano analisou.

\section{Palavras-chave}

Poder, soberania, vida, estado de exceção, nazismo. 


\section{Résumé}

Après une description détaillée du fonctionnement du pouvoir disciplinaire, Michel Foucault avance avec moins de précision dans la conceptualisation de la biopolitique, d'un type de régulation de population qui réduit la vie à ses dimensions biologiques. Reprenant mais aussi corrigeant ces développements, Giorgio Agamben établit une relation structurelle entre souveraineté et vie, avec pour intermédiaire l'Etat d'exception. Dans ce travail, je voudrais souligner que les concepts de souveraineté et d'état d'exception ne s'appliquent même pas au nazisme, seul exemple historique analysé par l’auteur italien.

\section{Mots clés}

Pouvoir, souveraineté, vie, Etat d'exception, nazisme.

\section{Introducción}

En la actualidad el concepto de biopolítica es uno de los más utilizados y redefinidos de la caja de herramientas foucaulteana. Es así que Mendiola Gonzalo detecta un peligroso ensanchamiento de la noción, pero, al mismo tiempo, advierte los riesgos de delimitar algo propio como la biopolítica: "Ante el primer caso, su potencia se pierde como consecuencia de un ensanchamiento que tan solo deja a su paso una creciente ambigüedad; en el segundo caso, su potencia se disipa como consecuencia de un reduccionismo" $(2009$, p. 8). Incluso, más que frente a un ensanchamiento conceptual, podría decirse que estamos en presencia de un concepto de moda, que hace algunos años solo era utilizado por un pequeño número de intelectuales, pero que, actualmente, se emplea en diferentes disciplinas y discursos (Lemke, 2011, p. 1), y esto puede hacer que pierda su identidad y se transforme en un enigma (Esposito, 2006, p. 27). Esta moda ha llevado a algunos autores a rechazar el empleo de la noción de biopolítica (Patton, 2007).

El ensanchamiento conceptual puede explicarse no solamente porque resulta indescifrable la relación entre vida y política sino porque además las definiciones mismas de vida y de política no son precisas: con la noción de vida no es fácil advertir si la referencia es a la vida biológica (zoé) o a la cualificada (bíos) o a ambas, y mucho más escurridiza resulta la noción de política. Tampoco es sencillo establecer si los conceptos de política y vida son previos a su relación; esta modifica los conceptos, o estos emergen de la propia relación. 
En este trabajo reseñaré brevemente el modo en que Michel Foucault tematizó sobre el poder disciplinario y la biopolítica, para luego dar cuenta de la manera en que Giorgio Agamben retoma y redefine a este último. Presentaré los densos conceptos de soberanía, nuda vida, homo sacer y estado de excepción, y luego mostraré ciertos problemas al momento de emplear las nociones de soberanía y excepción en uno de los pocos ejemplos históricos mencionados por Agamben. Me interesará señalar que los lúcidos aportes del autor italiano se mueven en un registro eminentemente conceptual generalmente despreocupados por las prácticas históricas concretas y ni siquiera uno de los pocos casos históricos acuñados, el estado de excepción dictado en la Alemania de Hitler, se inscribe en las conceptualizaciones de soberanía y excepción.

\section{Disciplinas y biopolítica en Michel Foucault}

Marc Kelly indica que, a diferencia de otras perspectivas, la propuesta de Foucault es estudiar al poder como un dominio en sí mismo (2009, p. 37), pero quizás habría que precisar que el propio autor francés ha sostenido que, aunque se habían analizado las vinculaciones entre el poder y otras variables - como los procesos económicos- faltaba investigar las relaciones de poder que se ejercen sobre los cuerpos (Foucault, 2001a, p. 1530). De hecho, la referencia a una microfísica apunta a conceptualizar un tipo de ejercicio del poder que "llega al grano mismo de los individuos, alcanza su cuerpo, llega a integrarse en sus gestos, sus actitudes, sus discursos, su aprendizaje, su vida cotidiana” (Foucault, 2001b, p. 1609).

Si bien el ejercicio del poder sobre el cuerpo ya existía durante el feudalismo, había indiferencia sobre la salud y los comportamientos corporales, pero a partir del siglo XVIII se desarrollaron "técnicas para adiestrar y para vigilar a los individuos en sus comportamientos corporales" (Foucault, 2001c, p. 586). A partir de entonces, las distintas instancias de ejercicio de poder se preocuparon por el cuerpo "de un modo completamente nuevo, bajo la forma del adiestramiento, de la vigilancia permanente y del rendimiento" (Foucault, 2001c, p. 587). A este control sobre el cuerpo que asegura "la sujeción constante de sus fuerzas y les imponen una relación de docilidad-utilidad, es a lo que se puede denominar las 'disciplinas"” (Foucault, 1975, p. 139). Las disciplinas no aspiran solamente a un crecimiento de las habilidades del cuerpo, sino también a la "formación de una relación que, en el propio mecanismo, lo torne más obediente cuanto más útil, y a la inversa” (Foucault, 1975, p. 139). Es así 
que "la disciplina aumenta las fuerzas del cuerpo (en términos económicos de utilidad) y disminuye sus mismas fuerzas (en términos políticos de obediencia)" (Foucault, 1975, p. 140).

En sus trabajos más refinados sobre las relaciones depoder en la Modernidad, Foucault enfatizó sobre el modo en que el cuerpo se había transformado en su blanco. Con menos precisión, en trabajos posteriores a Vigilar y castigar incluyó a este poder sobre el cuerpo como una de las dimensiones del poder sobre la vida, que denominó biopoder. Fue dentro de este marco más amplio que, además de un poder disciplinario, dio cuenta de una biopolítica de las poblaciones.

La noción de biopolítica antecede a la obra de Foucault, pero a sus trabajos se debe que hoy la categoría atraviese un notable ensanchamiento, hecho que contrasta con el escaso tratamiento que le ha brindado. En sus libros, la palabra biopolítica aparece únicamente en tres oportunidades en Historia de la sexualidad I. La voluntad de saber, y de las más de tres mil páginas que ocupan sus libros el tratamiento de la biopolítica abarca solo quince. Si se suman los Dichos y escritos y los cursos dictados en el Collège de France, la palabra se usa en 56 oportunidades, y biopoder, en 49 (Castro, 2011, pp. 40-41). Sobre este punto, para agregar problemas a la desprolijidad conceptual que sufre la categoría, en "Hay que defender la sociedad" y en Seguridad, territorio, población, Foucault utiliza la noción de biopoder en un sentido restringido, como sinónimo de biopolítica (1997, pp. 220, 221; 2004, pp. 3, 23). Sin embargo, en Historia de la sexualidad I, biopoder aparece en términos amplios, incluyendo la noción de biopolítica y también la de anatomopolítica o disciplina (1976, pp. 183184). Finalmente, en Las relaciones de poder penetran al interior de los cuerpos emplea la noción de "somato-poder" para referirse al biopoder en sentido amplio (2001d, p. 231). Además, no hay que olvidar que estudió la biopolítica en el marco de problemáticas muy diferentes: la medicina social, la guerra de razas, la emergencia del liberalismo, etc. (Antonelli, 2012, p. 27).

La primera vez que analizó la biopolítica fue en El nacimiento de la medicina social, una conferencia dictada en octubre de 1974 en la Universidad del Estado de Río de Janeiro. Allí la conceptualización fue superficial y apuntaba a dar cuenta del control de la medicina sobre las dimensiones corporales y biológicas de la humanidad (Foucault, 2001e, pp. 209-210). Por su lado, la 
última vez que se refirió al biopoder fue en una entrevista que le realizaron en 1983, donde mencionaba que debía realizar una genealogía del biopoder, pero no contaba con tiempo para ello (Foucault, 1983, p. 232). Aunque falleció al año siguiente sin haber desarrollado su estudio genealógico, a partir del $\mathrm{V}$ capítulo del primer volumen de Historia de la sexualidad y de la clase del 17 de marzo de 1976 del curso "Hay que defender la sociedad", es posible delinear los contornos de la biopolítica.

La tematización que aparece en Derecho de muerte y poder sobre la vida sobre la biopolítica se realiza a partir de la comparación con el poder soberano. Uno de los privilegios de la soberanía era el derecho de vida y de muerte sobre sus súbditos, y funcionaba de modo disimétrico: el derecho sobre la vida solo se ejerce poniendo en acción el derecho sobre la muerte. De algún modo, "el derecho que se formula como 'de vida y de muerte' es, de hecho, el derecho de hacer morir o de dejar vivir" (Foucault, 1976, p. 178). No se trata de un derecho que hace vivir y morir, ni que deja vivir y morir, sino que "se ejerce de una manera desequilibrada, siempre del lado de la muerte" (Foucault, 1997, p. 214). Es así que en el siglo XIX se configuró "un poder exactamente inverso: poder de hacer vivir y dejar morir” (Foucault, 1997, p. 218).

Aquel poder que se relacionaba con la vida a partir de su posibilidad de quitarla debe enmarcarse en un contexto en el cual el poder se ejercía de modo soberano: a partir de la apropiación de riquezas, productos, servicios y trabajo de los individuos. En la Modernidad, esos mecanismos de poder se transformaron y comenzaron a incrementar y ordenar las fuerzas de los hombres, trayendo consecuencias en la relación entre la vida y la muerte: "El viejo derecho de hacer morir y dejar vivir ha sido sustituido por un poder de hacer vivir o de rechazar a la muerte" (Foucault, 1976, p. 181) ${ }^{1}$. Este poder sobre la vida se desarrolló bajo dos polos complementarios: el primero, las disciplinas o la anátomopolítica del cuerpo humano, que se centró en el cuerpo como máquina, buscó incrementar sus fuerzas y aptitudes, y su integración a sistemas económicos. El segundo, la biopolítica de las poblaciones, se formó más tarde y se focalizó "sobre el cuerpo-especie, sobre el cuerpo atravesado por la mecánica de lo viviente y sirviendo de soporte a los procesos biológicos" (Foucault, 1976, p. 183). Las disciplinas del cuerpo y la biopolítica de las poblaciones "constituyen

$1 \quad$ A modo de pequeño matiz puede mencionarse que, si en Historia de la sexualidad I se muestra una discontinuidad entre la soberanía y la biopolítica, en "Hay que defender la sociedad" alude a una imbricación entre ambos dispositivos (Foucault, 1997, p. 214). 
los dos polos alrededor de los cuales se desarrolló la organización del poder sobre la vida” (Foucault, 1976, p. 183)².

La biopolítica no tiene como blanco el cuerpo sino la vida reducida a su componente biológico, y si bien, al igual que las disciplinas se dirigen a la multiplicidad, esta no es desagregada en cuerpos individuales sino que es tomada como una masa global. En términos genéricos, a este poder que hace vivir y deja morir Foucault lo llama poder de "regularización”. Los fenómenos que se intentan regular —natalidad, morbilidad, relación de la población con el medio- son aleatorios e imprevisibles si se los toma en su particularidad, pero desde el punto de vista colectivo y a largo plazo se pueden establecer regularidades (Foucault, 1997, pp. 219-220).

A primera vista parece difícil afirmar que, a partir del siglo XVIII, la preocupación del poder ha sido "hacer vivir", cuando en el siglo XX se desplegaron terribles genocidios. De todos modos, la apuesta de Foucault es mostrar que ellos, en particular el nazi, muestran al Estado aniquilando biopolíticamente, matando para proteger la vida: el poder de muerte se despliega "como el complemento de un poder que se ejerce positivamente sobre la vida” (1976, p. 179). En la era del biopoder, las guerras no se desatan para defender al soberano sino "en nombre de la existencia de todos [...] Las masacres han devenido vitales” (1976, p. 180). A través de la apropiación del racismo, los genocidios no se configuraron como un poder que se ejerce sobre la vida. Dicho de otro modo, si el biopoder desea reapropiarse del poder de dar muerte debe hacerlo a través del racismo, que es la precondición para que el Estado se transforme en un agente de muerte (Taylor, 2011, p. 50).

El racismo biologicista funciona como un medio para introducir un corte entre lo que debe vivir y lo que debe morir, y establece una relación positiva del tipo "cuanto más mates o dejes morir, más vivirás". Suscita una relación estrictamente biológica entre vida y muerte: "La muerte del otro, la muerte de la mala raza, de la raza inferior (o del degenerado o el anormal), es lo que

2 Nuevamente para marcar sutilezas, en La voluntad de saber el biopoder se articula con el funcionamiento de dos polos —estamos frente a un "poder bipolar" —, pero en "Hay que defender la sociedad" no alude a una bipolaridad sino a dos tecnologías que funcionan de modo superpuesto (Castro-Gómez, 2010, pp. 56-57, Foucault, 1997, p. 222). En Las mallas del poder no refiere a un poder bipolar ni a tecnologías superpuestas, sino a dos innovaciones en una misma tecnología de poder (Foucault, 2001f, p. 1013). Siempre en el sendero de marcar detalles, al momento de realizar una comparación no debemos olvidar que mientras que La voluntad de saber es un libro, "Hay que defender la sociedad" es un curso, y Las mallas del poder, una conferencia, y puede que los grados de precisión no sean similares. 
va a tornar la vida en general más sana” (Foucault, 1997, p. 228). El racismo configura una relación peligrosa entre la raza verdadera y las restantes subrazas, y para proteger a la primera resulta necesario aniquilar a las otras (Lemke, 2011, p. 42). Instituye un enfrentamiento estrictamente biológico, y por ello los adversarios no son enemigos políticos sino peligros biológicos (Foucault, 1997, p. 228).

Si bien podría brindar mayores precisiones del desarrollo de la biopolítica y la tanatopolítica, me interesa restituir el modo en el que Agamben enuncia una serie de correcciones a los trabajos de Michel Foucault, para luego sugerir que sus aproximaciones conceptuales no son aplicables ni siquiera para el caso del nazismo, especialmente estudiado en los trabajos del italiano.

\section{Biopolítica y soberanía. Los aportes de Giorgio Agamben}

En la introducción de Homo sacer I, Agamben sugiere que los griegos no disponían de un único término para expresar lo que actualmente representa el vocablo vida sino que utilizaban dos nociones: zoé, para referirse a la vida biológica común a todos los seres vivos, y bíos, que daba cuenta de una vida calificada $^{3}$. El mundo clásico estaba familiarizado con la idea de una vida natural, aunque quedaba excluida de la polis (1998, pp. 9-10, 2001a). Sin embargo, su apuesta es mostrar que, por la estructura de bando que implica la soberanía, esa vida biológica aparentemente desligada de la política se incluye en la esfera de la soberanía a partir de su exclusión (Edkins, 2007, p. 75).

Agamben afirma que, mientras Foucault detectaba que en la Modernidad la vida natural se incluía en los cálculos del poder estatal, Arendt había mostrado cómo la vida biológica, en desmedro de una vida activa, comenzaba a ocupar el centro de la escena política moderna (Arendt, 1998, 1961, p. 150). No obstante, así como ella no había articulado estas ideas con sus reflexiones sobre el poder totalitario, Foucault tampoco había investigado los espacios biopolíticos por excelencia: los campos de concentración y la estructura de los estados totalitarios.

3 Para Leland de la Durantaye, que existiera más de una palabra para referirse a la vida no causa sorpresa, porque las lenguas antiguas suelen presentar más de un vocablo para dar cuenta de lo mismo. De todos modos, como aclara, bíos y zoé no refieren a la vida en un mismo sentido (2009, pp. 204-205). 
Agamben muestra el modo en que Foucault abandona la perspectiva jurídicoinstitucional y estudia los modos en que el poder penetra el cuerpo, y cómo en la década de 1980 sus análisis se dirigieron a la interrelación entre las técnicas políticas y las tecnologías del yo. Para el autor italiano estas dos tecnologías "se entrelazan en muchos puntos y remiten a un centro común" (1998, p. 14), pero estos núcleos de convergencia no han sido analizados, ya que si se rechaza el modelo jurídicopolítico de la soberanía, “¿dónde está entonces, en el cuerpo del poder, la zona de indiferencia (o, por lo menos, punto de intersección) en que se tocan las técnicas de individualización y los procedimientos totalizantes?” (1998, p. 15) ${ }^{4}$. Agamben no sostiene que Foucault descuidó la perspectiva jurídica política sino que la abandonó conscientemente, y entiende que el análisis de las estructuras legales puede servir como complemento a los desarrollos del autor francés (de la Durantaye, 2007, p. 209). Desde esta perspectiva, la investigación por desarrollar en la saga Homo sacer "se refiere precisamente a ese punto oculto en que confluyen el modelo jurídico institucional y el modelo biopolítico del poder” (Agamben, 1998, p. 16). Una de las conclusiones que se obtienen indica que esas variables no pueden separarse $\mathrm{y}$

que las implicaciones de la nuda vida en la esfera política constituyen el núcleo originario —aunque oculto— del poder soberano. Se puede decir, incluso, que la producción de un cuerpo biopolítico es la aportación original del poder soberano. La biopolítica es, en este sentido, tan antigua al menos como la excepción soberana”. (Agamben, 1998, p. 16)

Cuando el Estado moderno toma a la vida biológica en el centro de sus cálculos no hace más que sacar a la luz el vínculo constitutivo que existe entre la soberanía y la nuda vida, puesto que el aporte decisivo del "poder soberano es la producción de la nuda vida como elemento político original” (Agamben, 1998, p. 53). La nuda vida es producida por la soberanía, pero, además, el poder sobre esta es lo que define la soberanía (Fitzpatrick \& Joyce, 2007, p. 68). Si para Foucault la biopolítica es un fenómeno cuya emergencia se localiza en la Europa moderna, para Agamben es tan antigua como la soberanía. Por ello, la tesis foucaulteana debe ser completada, ya que lo que caracteriza a la Modernidad no es la inclusión de la vida biológica en la política sino

$4 \quad$ Entre los trabajos que no admiten que Foucault realice una separación entre las tecnologías gubernamentales y las del yo, ver Vázquez García (2005, pp. 80-84) y Castro Orellana (2010). 
el hecho de que, en paralelo al proceso en virtud del cual la excepción se convierte en regla, el espacio de la nuda vida que estaba situada originalmente al margen del orden jurídico, va coincidiendo de manera progresiva con el espacio político, de forma que exclusión e inclusión, externo e interno, bíos y zoé, derecho y hecho, entran en una zona de irreductible indiferenciación. (Agamben, 1998, pp. 18-19)

El estado de excepción, mecanismo por el cual la vida es excluida y apresada por el orden jurídico, constituye "el fundamento oculto sobre el que reposaba todo el sistema político” (Agamben, 1998, p. 19) y lo propio de la Modernidad es que ese espacio de excepción se presenta cada vez más como una regla.

Teniendo en cuenta las conclusiones a las que Agamben pretende llegar, es necesario presentar las nociones de soberanía, estado de excepción y nuda vida.

\section{La estructura paradojal de la soberanía}

Para conceptualizar la soberanía, Agamben retoma los lineamientos trazados por Carl Schmitt, quien había definido al soberano como "quien decide sobre el estado de excepción” (Schmitt, 2009, p. 13). De esto se deriva que el derecho no tiene fundamento en una norma sino en una decisión (Naishtat, 2008), la cual es estrictamente individual (Galindo Hervás, 2005, p. 26), y que para el autor italiano se presenta con la misma estructura en los Estados democráticos y no democráticos (Swiffen, 2011, p. 168). El funcionamiento de la soberanía implica una paradoja cuya formulación indica que "el soberano está, al mismo tiempo, fuera y dentro del ordenamiento jurídico'” (Agamben, 1998, p. 27). Soberano es aquel a quien el ordenamiento jurídico reconoce la facultad de declarar el estado de excepción y suspender así su propia vigencia, lo que implica que el soberano "se sitúa legalmente fuera de ella" (Agamben, 1998, p. 27). Dado que el soberano se ubica fuera de la ley y suspende legalmente el orden jurídico, la paradoja de la soberanía pueda adoptar otras dos formulaciones: "la ley está fuera de sí misma', o bien: 'Yo, el soberano, que estoy fuera de la ley, declaro que no hay un afuera de la ley" (Agamben, 1998$, p. 27$)^{5}$. A raíz de esta paradoja, la soberanía debe tenerse como un “concepto-límite" cuya estructura puede ejemplificarse a través de la forma de la excepción (Agamben, 2007, p. 327).

\footnotetext{
$5 \quad$ Una primera presentación de la paradoja de la soberanía puede encontrarse en una conferencia que Agamben brindó en 1986 en el Centro Cultural Francés de Roma (2012, pp. 19-20).
} 
La excepción es un tipo de exclusión que supone que un caso individual es excluido de la norma general, pero aquello que es excluido no se desconecta de la norma: "se mantiene en relación con ella en la forma de la suspensión. La norma se aplica a la excepción desaplicándose, retirándose de ella” (Agamben, 1998, p. 30). La excepción es compleja porque lo que permite que un caso particular se mantenga incluido es la propia suspensión del orden jurídico. Agamben denomina “'relación de excepción' a esta forma extrema de la relación que solo incluye algo a través de su exclusión” (1998, p. 31). La situación creada por la excepción no es de hecho ni de derecho, sino que establece entre ambos planos "un paradójico umbral de indiferencia" (1998, p. 31). Con la estructura de la excepción el orden jurídico incluye al caos, y esta zona de indistinción se transforma en condición de posibilidad para delimitar lo que está fuera y lo que está dentro (1998 pp. 31-32, 2006, p. 75). En el estado de excepción es imposible distinguir entre dentro y fuera, norma y excepción, hecho y derecho (2004a, p. 67), lo que trae como consecuencia la imposibilidad de delimitar "la transgresión de la ley y su ejecución, de manera de lo que está conforme a la norma y lo que la viola, coincidan sin fisuras" (1998, p. 78).

Si hasta aquí se advierten similitudes entre la presentación de Agamben y la de Schmitt, el autor italiano agrega un elemento que no se encuentra en los trabajos del alemán: la vida queda implicada en la esfera del derecho "solo a través de la presuposición de una exclusión inclusiva, solo en una exceptio" (Agamben, 1998, pp. 41-42)6. Si la excepción es la estructura de la soberanía, es también "la estructura originaria en que el derecho se refiere a la vida y la incluye en él por medio de la propia suspensión” (Agamben 1998, p. 43). El estado de excepción, entonces, es el modo en que "el derecho incluye la vida; ya que esta, en tanto zoe, es intrínsecamente ajena a la ley, el derecho solo puede incluirla suspendiendo la ley" (Bacalarett Pérez, 2010, p. 37). La excepción es una relación de bando, y quien está en situación de bando no está fuera de la ley "sino que es abandonado por ella, es decir que queda expuesto y en peligro en el umbral en el que vida y derecho, exterior e interior se confunden” (Agamben, 1998, p. 44).

Si bien los conceptos de soberanía, estado de excepción y nuda vida están estructuralmente relacionados, en lo que sigue delimitaré con mayor precisión el estado de excepción y, luego, al homo sacer.

6 Lo que Agamben "añade a Schmitt es la consideración de que, en tal marco de excepcionalidad, la operación esencial del poder es el aislamiento, en cada sujeto, de su nuda o mera vida" (Galindo Hervás, 2005, p. 49). También puede consultarse Fitzpatrick \& Joyce (2007, p. 10). 


\section{El estado de excepción}

En la medida en que el estado de excepción es el dispositivo mediante el cual "el derecho se refiere a la vida y la incluye dentro de sí por medio de la propia suspensión" (Agamben, 2004a, p. 24), es urgente delimitar una teoría que explique aquello que vincula, y a la vez abandona, la vida y el derecho. Hay que analizar la estructura del estado de excepción y sacar a la luz la "oculta, pero fundamental relación entre ley y ausencia de ley” (Agamben, 2010a, p. 42). Tras presentar un debate académico sobre su carácter interno o externo al orden jurídico, Agamben plantea que el conflicto que se suscita en torno a su conceptualización se explica por ese umbral en donde el adentro y el afuera "se indeterminan. La suspensión de la norma no significa su abolición, y la zona de anomia que ella instaura no está (o al menos pretende no estar) totalmente escindida del orden jurídico" (2004a, p. 59). Para avanzar en una conceptualización que permita dar luz a este umbral, esta zona de indistinción, Agamben retoma nuevamente los trabajos de Schmitt.

En La dictadura, escrito en 1921, Schmitt presenta al estado de excepción a partir de las dos figuras que puede adquirir la dictadura: comisarial o soberana. La comisarial tiene por objeto suspender la Constitución para proteger su existencia, pero aún suspendida, mantiene su aplicación y vigencia (Agamben, 2004, p. 73)7. La soberana no busca sostener la vigencia de la constitución sino crear una situación en la cual sea imposible imponer una nueva, de lo cual emerge una suerte de poder constituyente que, aunque no surja de la Constitución, mantiene un nexo con ella (Agamben, 2004a, p. 74) ${ }^{8}$. En Teología política, publicado en 1922, el operador que inscribe al estado de excepción dentro del ordenamiento jurídico es la distinción entre norma y decisión, y esto permite explicar por qué la teoría del estado de excepción es una doctrina de la soberanía: "El soberano, que tiene el poder de decidir sobre el estado de excepción, garantiza el anclaje al orden jurídico” (Agamben, 2004a, p. 75). De este modo, retomando la paradoja de la soberanía, "el soberano se sitúa

7 Schmitt retoma la noción de dictadura comisarial desarrollada por Bodin, pero también la redefine, porque mientras para este el dictador es un simple funcionario para Schmitt es menester distinguirlos: "El funcionario ordinario está sujeto a la ley, y la decisión que él adopte en el caso singular no es más que la concreción de una decisión general adoptada ya previamente por la ley. En cambio, en el comisario lo primero que se verifica en el caso singular es cómo pone en acción su decisión. El comisario está, pues, aparentemente menos ligado, es más libre que el funcionario ordinario, quien no puede traspasar el marco de una actividad legalmente regulada" (1985, p. 68).

8 La dictadura comisarial tiene filiación con un poder constituido, mientras que la dictadura soberana, con unoconstituyente: "El dictador comisarial es el comisario de acción incondicionado de un pouvoir constitué [poder constituido]; la dictadura soberana es la comisión de acción incondicionada por un pouvoir constituant [poder constituyente]" (Schmitt, 1985, p. 193). 
fuera del orden jurídico, pero, en cuanto responsable de su suspensión, está al mismo tiempo incluido" (Castro, 2008, p. 68). Sin embargo, la figura del soberano es todavía más compleja, puesto que no solamente puede declarar el estado de excepción, sino que "está en realidad lógicamente definido en su ser por este" (Agamben, 2004a, p. 75). Es así que "el rango y la paradoja del concepto schmittiano de soberanía derivan, como hemos visto, del estado de excepción, y no viceversa” (Agamben, 2004a, p. 76).

En los desarrollos de Teología política, con la decisión sobre el estado de excepción la norma se suspende y ello hace posible su aplicación: "Introduce en el derecho una zona de anomia para hacer posible la normación" (Agamben, 2004a, p. 76). En el estado de excepción hay una relación inversamente proporcional entre la vigencia de la norma y su aplicación: "Es un campo de tensiones jurídicas en el cual un mínimo de vigencia formal coincide con un máximo de aplicación real y viceversa” (Agamben, 2004a, p. 76).

El paradigma del estado de excepción, y desde el cual se puede proyectar una "teoría general," es el iustitium, una particular institución de la República romana. Si bien no me interesa realizar una caracterización tal instituto, es a partir de este que Agamben enuncia una serie de tesis que supuestamente caracterizan al estado de excepción en todo tiempo y lugar: a- no es una forma de dictadura "sino un espacio vacío de derecho, una zona de anomia en la cual todas las determinaciones jurídicas [...] son desactivadas" (2004a, p. 99); b- este espacio vacío es esencial para el orden jurídico, que trata de asegurarse una relación con aquel, intenta "a cualquier costo de no dejarlo escapar" (2004a, p.100); c- resulta problemática la configuración jurídica de los actos cometidos durante el estado de excepción, ya que "en cuanto no son transgresivos ni ejecutivos ni legislativos, parecen situarse con respecto al derecho, en un absoluto no-lugar" (2004a, p. 100); d- la suspensión del derecho libera un maná jurídico que intenta ser capturado mediante la construcción ficciones como fuerza-de-ley, vigencia sin aplicación, y otras figuras con las cuales "el derecho intenta incluir en sí la propia ausencia y apropiarse del estado de excepción, o cuanto menos, asegurarse una relación con él” (2004a, pp. 100-101).

Expuesta la estructura de la soberanía y el estado de excepción, resta analizar la relación de abandono que la soberanía guarda con la nuda vida. Para avanzar sobre este punto, Agamben se remonta hasta el derecho romano arcaico y da cuenta de la figura del homo sacer, que ya había mencionado hacia el final de El lenguaje y la muerte (2002, p. 168), en un pasaje de La comunidad 
que viene (1996, p. 55), y que le permite mostrar cómo en el "sistema jurídico se hace presente la relación de exclusión o de bando que [...] sería propia de la lógica de la soberanía” (Quintana Porrás, 2006, p. 49).

\section{El homo sacer}

En el tratado Sobre la significación de las palabras de Festo se encuentra un pasaje en el cual la sacralidad se asocia con la vida humana, y se lee que "hombre sagrado es, empero, aquel a quien el pueblo ha juzgado por un delito; no es lícito sacrificarle, pero quien le mate, no será condenado por homicidio"” (Agamben, 1998, p. 94). Para Agamben, la particularidad del homo sacer es "la impunidad de darle muerte y la prohibición de su sacrificio" (1998, p. 96), ${ }^{9}$ y además, su propuesta es estudiar la sacralidad como una figura autónoma, previa a la distinción entre lo profano y lo sagrado, lo jurídico y lo religioso (1998, pp. 96-97, 2010b, pp. 25-34). La estructura de la sacratio es el resultado de la impunidad de matar y la exclusión del sacrificio, lo que configura una excepción respecto del derecho profano y del divino, y al igual que la excepción soberana, "la ley se aplica al caso excepcional desaplicándose, retirándose de él” (1998, p. 107).

Agamben ya había mostrado que la decisión soberana suspendía la ley y con ello incluía a la vida en la esfera jurídica. Ahora relaciona la soberanía con la sacralidad, y es por ello que, luego de sugerir que "el homo sacer ofrece la figura originaria de la vida apresada en el bando soberano” (1998, p. 109) agrega que "soberana es la esfera en que se puede matar sin cometer homicidio y sin celebrar un sacrificio; y sagrada, es decir, expuesta a que se le dé muerte, pero insacrificable, es la vida que ha quedado prendida en esta esfera” (1998, p. 109). Aquello que queda apresado en el bando soberano es el homo sacer, lo que nos permite advertir que sagrada es "la vida incluida en el bando soberano, y la producción de la nuda vida es, en este sentido, la contribución originaria de la soberanía" (Agamben, 1998, p. 109). De esta manera, el homo sacer "no es un problema político, sino un problema de lo político” (Rash, 2007, p. 102).

\section{Biopolítica y totalitarismo}

Una de las apuestas teóricas más audaces enunciadas por Agamben es mostrar que las democracias y los estados totalitarios comparten la misma

$9 \quad$ El homo sacer es "el sitio de una conjunción entre una capacidad pasiva (se le puede matar), con una incapacidad pasiva (no puede ser sacrificado)" (Schütz, 2011, p. 95). 
estructura jurídicopolítica. Las variables a partir de las cuales tematiza la vinculación entre biopolítica y totalitarismo son los derechos del hombre, las prácticas de eugenesia e investigaciones científicas durante el nazismo, y los debates alrededor del concepto de muerte. Aunque no podré tematizar estas variables, sí merece enunciarse su mirada sobre el nazismo y los campos de concentración.

Agamben no se propone describir lo que ha sucedido en los campos sino analizar su estructura jurídicopolítica. La biopolítica nazi y el funcionamiento del campo muestran la forma que adquiere la administración de la vida es el estado de excepción, pero, además, nos permiten concebir al campo no solamente como una aberración sino "como la matriz oculta, el nómos del espacio político en que vivimos todavía” (1998, p. 212). Se discute sobre el origen histórico de los campos, pero cualquiera sea, emergieron en estados de excepción enmarcados en luchas coloniales. Situación similar ocurre con el caso nazi, ya que la base jurídica del internamiento fue la Schutzhaft - custodia protectora-, que tenía origen en la ley prusiana del 4 de junio de 1851. Su fundamento jurídico era la proclamación del estado de sitio o excepción previsto en el Artículo 48 de la Constitución de la República de Weimar, que como fue utilizada por los gobiernos republicanos, cuando el 28 de febrero de 1933 los nazis promulgaron el Decreto para la protección del pueblo y del Estado, continuaron una práctica que ya existía. Agamben ubica al totalitarismo dentro de la legalidad vigente, pero marca una nota distintiva: si bien el decreto parecía fundarse en el Artículo 48, no contenía referencias a un estado de excepción y se mantuvo vigente doce años. De esta manera, el estado de excepción deja de referirse a un peligro real "y tiende a confundirse con la propia norma” (1998, p. 214). La custodia protectora se desliga de las situaciones excepcionales y se mantiene vigente en situaciones de normalidad, lo que permite afirmar, con resonancias de benjaminianas, que "el campo de concentración es el espacio que se abre cuando el estado de excepción empieza a convertirse en regla” (1998, p. 215). De este modo, el campo es "el lugar en que el estado de excepción coincide perfectamente con la regla y en que la situación extrema se convierte en el paradigma mismo de lo cotidiano" (2000, p. 50). Finalmente, ya sin referencias al nazismo, puede decirse que el estado de excepción “ocupa cada vez más el primer plano en nuestro tiempo y tiende, en último término, a convertirse en la regla” (1998, pp. 32-33).

En la medida en que los moradores del campo carecían de protección jurídica y eran reducidos a una nuda vida, el campo representa el "más absoluto espacio biopolítico que se haya realizado nunca, en el que el poder no 
tiene frente a él más que la pura vida sin mediación alguna” (Agamben, 1998, p. 218). No es correcto preguntarse cómo fue posible que se hayan cometido delitos aberrantes dentro del campo, sino que hay que interrogarse sobre los procedimientos jurídicos que permitieron que esas acciones no fueran consideradas delitos (Agamben, 2001b, p. 40). De este modo, si lo característico del campo es la materialización del estado de excepción y la creación de un espacio en el que la nuda vida y la norma no pueden diferenciarse, este se configura cada vez que se crea una estructura con esas características con independencia de los crímenes que se cometan. Es por ello que, para Agamben, "el campo de concentración y no la ciudad es hoy el paradigma biopolítico de Occidente” (1998, p. 230).

\section{Excepción y soberanía: conceptos sin prácticas}

En Signatura rerum, cuyo subtítulo es Sobre el método, Agamben sostiene que las figuras del homo sacer y el estado de excepción, más allá de tener cierta positividad histórica, habían sido utilizadas como paradigmas, "cuya función era la de constituir y hacer inteligible la totalidad de un contexto histórico-problemático más vasto" (2009, p. 13). Es así que "el paradigma es un caso singular que es aislado del contexto del que forma parte solo en la medida en que, exhibiendo su propia singularidad, vuelve inteligible un nuevo conjunto, cuya homogeneidad él mismo debe constituir" (2009:25). Si el objetivo de Agamben es recuperar la teoría de la soberanía y las reflexiones sobre el derecho "para comprender nuestra situación presente" (2004b, p. 14) creo que no se pueden descuidar las prácticas y el funcionamiento concreto de la soberanía. Si concebimos a la soberanía y al estado de excepción como paradigmas, los casos individuales escogidos - la soberanía y el estado de excepción en el Tercer Reich- deberían cumplir con todas y cada una de las dimensiones conceptuales enunciadas. Sin embargo, veremos que el caso nazi, el caso paradigmático, no plasma todas las implicancias conceptuales del Estado de excepción. Del mismo modo, también quedará clara la dificultad de utilizar un caso de soberanía individual — la del DritteReich — como paradigma para hacer inteligible el esquema de las soberanías contemporáneas, que difícilmente puede afirmarse que sean individuales.

Cuando Foucault ubica, a fines del siglo XVIII, la preocupación por el hacer vivir, es consciente que esta ya estaba presente en el contractualismo, pero le interesaba rastrear la atención del poder hacia la vida en el plano "no de la teoría política sino, más bien, a nivel de los mecanismos, las técnicas, las 
tecnologías de poder" (1997, 215). A contrapelo de esta propuesta, Agamben no se ha molestado en estudiar el funcionamiento y los mecanismos de la soberanía y la excepción. Ha delineado un resbaladizo diseño conceptual, con categorías sofisticadas que difícilmente puedan corresponderse con alguna práctica jurídicopolítica concreta. En este sentido, creo que sus conceptualizaciones sobre la soberanía no pueden ni siquiera aplicarse para el caso del nazismo, y esto no es menor, porque el ejemplo nazi es uno de los pocos procesos históricos que Agamben enuncia para dar cuenta de sus conceptualizaciones.

Que casi no brinde pistas sobre la práctica soberana, que no tematice sobre la soberanía en un registro histórico, no es solo un problema en sí mismo, sino que la situación cobra mayor gravedad cuando advertimos que el concepto de soberano en la obra de Schmitt se concibe en términos estrictamente individuales. Además, el jurista alemán no inscribía sus desarrollos en un registro simplemente descriptivo, sino que tenía la pretensión de retornar a un esquema de soberanía unipersonal, al reafirmar la primacía del poder ejecutivo por sobre la tradición liberal de la separación de poderes (Derumeaux, 2010, p. 33). En varios trabajos, Schmitt propone separar al liberalismo de la democracia, y postula que el parlamentarismo y su forma de gobierno basada en la discusión se inscriben en la tradición del liberalismo, pero no en la democrática. La particularidad de la democracia no es la libertad ni la pluralidad sino la homogeneidad, y es por ello que una buena traducción institucional del ideal democrático es el modelo plebiscitario (2002, 2006).

El único soberano al que Agamben alude con nombre y apellido es Adolf Hitler (1998, pp. 147, 177, 178, 179, 185, 188, 189, 191, 215). Sin embargo, no lo menciona en la primera sección de El poder soberano y la nuda vida dedicada a "La lógica de la soberanía" y no aclara cómo un único soberano puede ilustrar la estructura jurídica que subyace a todos los ordenamientos jurídicos del mundo occidental. A simple vista la figura de Hitler como soberano parece difícilmente asimilable a otros, y también, en una primera lectura, la estructura jurídica que le permitió declarar el estado de excepción parece bastante particular. De todos modos, aquí me interesa remarcar que esa estructura jurídica se muestra lejana a las conceptualizaciones adelantadas por Agamben.

El ya mencionado Artículo 48 de la Constitución —aprobada el 31 de julio, promulgada el 9 de agosto y vigente desde el 14 de septiembre de 1919contemplaba que, si un Land no cumplía los deberes impuestos por el Reich, 
la Constitución o las leyes, "el presidente del Reich podrá hacer uso de las fuerzas armadas para compelerlo a hacerlo”. Además, estipulaba que

si la seguridad y el orden público al interior del Reich son severamente dañados o están en peligro, el presidente del Reich podrá tomar las medidas necesarias que lleven a restablecer el orden, interviniendo con la asistencia de las fuerzas armadas, de ser necesario. Para este propósito, podrá suspender temporalmente, totalmente 0 en parte, los derechos fundamentales proveídos en los artículos 114, 115, 117, 118, 123, 124 y 153.

De esta primera lectura queda claro que, aunque el presidente podía hacerlo con algunos artículos de la Constitución no estaba facultado para suspender el sistema jurídico en su totalidad. De acuerdo con la formulación de Agamben, el estado de excepción no es una suspensión de algunos derechos, de una parte del sistema legal, sino del ordenamiento jurídico en su conjunto, algo que no se lee en el Artículo 48. Es así que como no estamos frente a una suspensión completa del orden jurídico, no parecen configurarse esos umbrales de indistinción entre afuera y adentro, hecho y derecho, cumplimiento y violación de la ley, que serían característicos y constitutivos del estado de excepción. Salta a la vista, según creo, que ni siquiera el único ejemplo histórico invocado por Agamben se ajusta rigurosamente con las conceptualizaciones de soberanía y excepción.

Haciendo caso omiso a lo anterior, en esta primera lectura de la Constitución nos estaríamos acercando a un formato unipersonal de la soberanía. Parece ser que un único individuo puede declarar la suspensión parcial del sistema jurídico, y por ello estamos frente a un único soberano. De todos modos, es difícil encontrar estructuras jurídicas similares en las democracias contemporáneas, ya que —al menos en muchas de ellas- la suspensión de parte del orden jurídico no la realiza el presidente, no la lleva adelante un único soberano, sino el Parlamento - 0 al menos tiene facultad de revocación si la suspensión parcial la estableció el Poder Ejecutivo- ${ }^{10}$. Además, y esto es especialmente aplicable a los ordenamientos jurídicos de las últimas décadas, la suspensión parcial suele estar sujeta a controles judiciales y a

10 En las constituciones americanas modernas se advierte lo siguiente: en Argentina, en principio, es el Congreso el facultado para declarar el estado de sitio (art. 75, inc. 23), en México lo declara el presidente en acuerdo con los titulares de las secretarias de Estado, los departamentos administrativos, Procuraduría General de la República y la aprobación del Congreso (art. 29); en Panamá lo decreta el presidente con el acuerdo del gabinete, pero si dura más de 10 días el Congreso debe confirmarlo o revocarlo (art. 51); en Paraguay puede declararlo el presidente o el Congreso, pero si lo hace el Poder Ejecutivo el Parlamento debe ratificarlo (art. 288). 
limitaciones impuestas por tratados internacionales de derechos humanos ${ }^{11}$. De este modo, en las democracias contemporáneas difícilmente se localice un esquema de soberanía unipersonal como el que Agamben pretende describir “para comprender nuestra situación presente” (2004b, p. 14).

En el plano conceptual es claro que el soberano es quien decide sobre la excepción, pero si queremos localizarlo no sabemos si debemos concurrir al edificio del Parlamento, del Poder Ejecutivo, de una Casa Real, o del Poder Judicial. Estas incertidumbres son imposibles de aclarar en la obra de Agamben, quien no se molesta en brindarnos un mapa actualizado de la ubicación del soberano. Sin embargo, si leemos el Artículo 48 de la Constitución de Weimar de modo completo, el panorama se oscurece todavía más. Si los dos primeros párrafos acercaban al presidente del Reich al soberano agambeneano, en el tercero se lee que "el presidente del Reich debe informar al Reichstag sin demora sobre todas las medidas tomadas de acuerdo con los párrafos 1 y 2 de este artículo. Estas medidas pueden ser revocadas a petición del Reichstag”. Si las suspensiones pueden ser revocadas por el Parlamento, ya no parece que el presidente del Reich sea el soberano unipersonal conceptualizado por Schmitt y restituido por Agamben. Teniendo esto en cuenta, quizás sí puede afirmarse que la estructura jurídica de la República de Weimar se asemeja a las de las democracias contemporáneas, pero solo en la medida en que se distancia de las conceptualizaciones aportadas, o imaginadas, por Agamben.

11 En el contexto americano el artículo 27 de la Convención Americana sobre Derechos Humanos limita la declaración del estado de sitio de este modo: "1. En caso de guerra, de peligro público o de otra emergencia que amenace la independencia o seguridad del Estado parte, este podrá adoptar disposiciones que, en la medida y por el tiempo estrictamente limitados a las exigencias de la situación, suspendan las obligaciones contraídas en virtud de esta convención, siempre que tales disposiciones no sean incompatibles con las demás obligaciones que les impone el derecho internacional y no entrañen discriminación alguna fundada en motivos de raza, color, sexo, idioma, religión u origen social. 2. La disposición precedente no autoriza la suspensión de los derechos determinados en los siguientes artículos: 3 (derecho al reconocimiento de la personalidad jurídica); 4. (derecho a la vivienda); 5 (derecho a la integridad personal); 6 (prohibición de la esclavitud y servidumbre); 9 (principio de legalidad y de retroactividad); 12 (libertad de conciencia y de religión); 17 (protección a la familia); 18 (derecho al nombre); 19 (derechos del niño); 20 (derecho a la nacionalidad), y 23 (derechos políticos, ni de las garantías judiciales indispensables para la protección de tales derechos".

Desde lo global, el Artículo 4 del Pacto Internacional de Derechos Civiles y Políticos también limita la suspensión del orden jurídico: 1 . En situaciones excepcionales que pongan en peligro la vida de la Nación y cuya existencia haya sido proclamada oficialmente, los Estados partes en el presente pacto podrán adoptar disposiciones que, en la medida estrictamente limitada a las exigencias de la situación, suspendan las obligaciones contraídas en virtud de este pacto, siempre que tales disposiciones no sean incompatibles con las demás obligaciones que les impone el derecho internacional y no entrañen discriminación alguna fundada únicamente en motivos de raza, color, sexo, idioma, religión u origen social. 2. La disposición precedente no autoriza suspensión alguna de los artículos 6, 7, 8 (párrafos 1 y 2), 11, 15, 16 y 18". 


\section{Notas finales}

En este trabajo he presentado las aproximaciones de Michel Foucault al biopoder para luego enunciar las reformulaciones aportadas por Giorgio Agamben, uno de los autores más influyentes en el debate sobre la biopolítica contemporánea. Dentro de su esquema conceptual, las nociones de soberanía y estado de excepción resultan fundamentales para dar cuenta de la relación entre el poder y la vida, pero cuesta encontrar huellas históricas que encuadren con estas conceptualizaciones. Aunque de modo breve y poco detallado, el nazismo quizás sea el ejemplo histórico más empleado por el autor italiano, pero, de acuerdo con lo que intenté desarrollar, sus conceptualizaciones no resultan aplicables siquiera para dar cuenta de su estructura jurídicopolítica.

Como consecuencia de la arquitectura conceptual construida por Agamben, es posible proyectar una continuidad de la estructura jurídicopolítica de Occidente en la que la vida se incluye en la esfera de la soberanía a través del dispositivo de la excepción. Sin embargo, esta estructura que se presenta como idéntica a lo largo de toda la historia de la política occidental no resulta aplicable ni en el único ejemplo histórico acuñado por el propio autor italiano.

\section{Referencias}

Agamben, G. (1996). La comunidad que viene. Valencia: Pre-Textos.

. (1998). Homo sacer. I. El poder soberano y la nuda vida. Valencia: Pre-Textos.

. (2000). Lo que queda de Auschwitz. El archivo y el testigo. Homo sacer III. Valencia:

Pre-Textos.

. (2001a). Forma de vida. En Medios sin fin. Notas sobre la política. (pp. 13-20).

Valencia: Pre-Textos.

(2001b). ¿Qué es un campo? En Medios sin fin. Notas sobre la política. (37-43).

Valencia: Pre-Textos.

. (2002). El lenguaje y la muerte. Valencia: Pre-Textos, 2002.

. (2004a). Estado de excepción. Homo Sacer II, 1. Buenos Aires, Adriana Hidalgo, 2004a.

(2004b). Entrevista. En Estado de excepción. Homo sacer II, 1 (pp. 9-20). Buenos Aires: Adriana Hidalgo. 
(2006). Lo abierto. El hombre y el animal. Buenos Aires: Adriana Hidalgo.

. (2007). El mesías y el soberano. El problema de la ley en Walter Benjamin. En La potencia del pensamiento (pp. 323-343). Buenos Aires: Adriana Hidalgo.

. (2009). Signatura rerum. Sobre el método. Buenos Aires: Adriana Hidalgo.

. (2010a). Una entrevista con Giorgio Agamben (entrevista con Urlich Rauff). Derecho \& Barbarie, 3, pp. 42-45.

. (2010b). El sacramento del lenguaje. Arqueología del juramento, Homo sacer II, 3. Buenos Aires: Adriana Hidalgo.

. (2012). Bataille y la paradoja de la soberanía. En Teología y lenguaje. Del poder de Dios al juego de los niños (pp. 15-23). Buenos Aires: Las cuarenta.

Antonelli, M. (2012). Vida y poder en La volonté de savoir de Foucault. En E. Assalone,

P. Bedin (Eds.), Bíos y Sociedad I: Actas de la I Jornadas Interdisciplinarias de Ética y Biopolítica (pp. 26-31). Mar del Plata: Universidad Nacional de Mar del Plata.

Arendt, H. (1961). What is Freedom. En: Between Past and Future. Six Exercises in Political Thought (pp. 143-171). New York: The Viking Press.

. (1998). The Human Condition. Chicago: University of Chicago Press.

Bacarlett Pérez, M. (2010). Giorgio Agamben, del biopoder a la comunidad que viene. Araucaria. Revista Iberoamericana de Filosofía, Política y Humanidades, 24, pp. 29-52.

Castro, E. (2008). Giorgio Agamben. Una arqueología de la potencia. Buenos Aires: Unsam.

. (2011). Lecturas foucaulteanas. Una historia conceptual de la biopolítica. La Plata: Unipe.

Castro-Gómez, S. (2010). Historia de la gubernamentalidad. Razón de Estado, liberalismo y neoliberalismo en Michel Foucault. Bogotá: Siglo del Hombre Editores.

Castro Orellana, R. (2010). El dispositivo de la libertad. Intersticios, 32, pp. 27-40.

De la Durantaye, L. (2009). Giorgio Agamben. A Critical Introduction. Stanford: Stanford University Press.

Derumeaux, P. (2010). Norme et exception chez Giorgio Agamben: un philosophe face à l'État de droit (tesis para la maestría, Université Pierre Mendès France, Grenoble, Francia). 
Edkins, J. (2007) Whatever Politics. En M. Calarco, S. DeCaroli (Eds.), Giorgio Agamben. Sovereignty and Life (pp. 70-91). Stanford: Stanford University Press.

Esposito, R. (2006). Bíos. Biopolítica y filosofía. Buenos Aires: Amorrortu.

Fitzpatrick, P. Joyce, R. (2007). The Normality and the Exception in Democracy's Empire. Journal of Law and Society, 34, 1, pp. 65-76

Foucault, M. (1975). Surveiller et punir. Naissance de la prison. Paris: Gallimard. (1976). Histoire de la sexualité I. La volonté de savoir. Paris: Gallimard. . (1983). On Genealogy of Ethics: An Overview of Work in Progress. En H. Dreyfus, P. Rabinow, Michel Foucault: Beyond Structuralism and Hermeneutics. Chicago: The University Chicago Press.

. (1997). «ll faut défendre la société». Cours au Collège de France (1975-1976). Paris: Gallimard-Seuil.

. (2001a). Folie, une question de pouvoir. En Dits et écrits I (n. ${ }^{\circ} 141$, pp. 1528-1532). Paris: Gallimard.

. (2001b). Entretien sur la prison: le livre et sa méthode. En Dits et écrits I ( $n^{\circ} 156$, pp. 1608-1621). Paris: Gallimard.

. (2001c). La scène de la philosophie (entretien avec M. Watanabe). En Dits et écrits II ( $\mathrm{n}^{\circ} 234$, pp. 571-595). Paris: Gallimard.

. (2001d). Les rapports de pouvoir passent à l'intérieur des corps (entretien avec L. Finas). En Dits et écrits // (n 197, pp. 228-236). Paris: Gallimard.

. (2001e). La naissance de la médicine sociale. En Dits et écrits // ( . $^{\circ} 196$, pp. 207228). Paris: Gallimard.

. (2001f). Les mailles du pouvoir. En Dits et écrits I (n. ${ }^{\circ} 297$, pp. 1001-1020). Paris: Gallimard.

. (2004). Sécurité, territoire, population. Cours au Collège de France (1977-1978). Paris: Gallimard-Seuil.

Galindo Hervás, A. (2005). Política y mesianismo. Giorgio Agamben. Biblioteca Nueva: Madrid.

Kelly, M. (2009). The Political Philosophy of Michel Foucault. New York: Routledge.

Lemke, T. (2011). Biopolitical: An Advanced Introduction. New York: New York University Press. 
Mendiola Gonzalo, I. (2009). La biopolítica como un pensar fronterizo. En I. Mendiola Gonzalo (Ed.), Rastros y rostros de la biopolítica (pp. 7-29). Barcelona: Anthropos.

Patton, P. (2007). Agamben and Foucault on Biopower and Biopolitics. En M. Calarco, S. DeCaroli (Eds.), Giorgio Agamben. Sovereignty and Life (pp. 203-218). Stanford: Stanford University Press.

Quintana Porrás, L. (2006). De la nuda vida a la «forma-de-vida». Revista Argumentos, 52, pp. 43-60.

Rash, W. (2007). From Sovereign Ban to Banning Sovereignty. En M. Calarco, S. DeCaroli (Eds.), Giorgio Agamben. Sovereignty and Life (pp. 92-108). Stanford: Stanford University Press.

Schmitt, C. (2009). Definición de soberanía. En Teología política (pp. 13-20). Madrid: Trotta.

(1985). La dictadura. Madrid: Alianza.

. (2002). Sobre el parlamentarismo. Madrid: Tecnos.

(2006). Teoría de la Constitución. Madrid: Alianza.

Schütz, A. (2011). Homo sacer. En A. Murray, J. White, (Eds.), The Agamben Dictionary (pp. 94-96). Edinburgh: Edinburgh University Press.

Swiffen, A. (2011). Giorgio Agamben. Thought Between two Revolutions. En C. Barbour, G. Pavlich (Eds.) After Sovereignty (pp. 166-179). London and New York: Routledge.

Taylor, C. (2011). Biopower. En D. Taylor (Ed.), Michel Foucault. Key Concepts (pp. 41-52). Durkham: Acumen.

Vázquez García, F. (2005.). "Empresarios de nosotros mismos". Biopolítica, mercado y soberanía en la gubernamentalidad neoliberal. En J. Ugarte Pérez (Ed.), La administración de la vida. Estudios biopolíticos (pp. 73-103). Barcelona: Anthropos. 